\title{
La historia de Terri Schiavo Terri Schiavo's story
}

\author{
Fernando Novoa'
}

E I 31 de M arzo de 2005 muere Terri Schiavo de 41 años de edad en un hospital para enfermos terminales, 14 días después del retiro, por orden judicial, de la sonda a través de la cual fue alimentada durante los 15 años que permaneció en estado vegetativo.

Theresa M arie Schindler, su nombre de soltera, nació un 3 de diciembre de 1963 y en su adolescencia, estuvo obsesionada con la obesidad, llegando a pesar cerca de 90 kilos con 1,60 metros de estatura. Los esfuerzos dietéticos permitieron a Schiavo transformarse en una joven atractiva que conoció en 1982 a Michael Schiavo, cuando ambos estudiaban. Terri, de religión católica, contrajo matrimonio con Michael, luterano, cuando ella tenía 20 años y él 21.

La mujer supuestamente desarrolló un desorden alimenticio, según se infiere de los documentos consignados en un tribunal por una demanda de negligencia médica. El matrimonio comenzó a confrontar problemas para tener hijos y Terri, que en esa época pesaba 49 kilos, consultó con un médico especializado en fertilidad, porque su menstruación se había detenido.

El 25 de febrero de 1990, Schiavo sufre un paro cardíaco y su cerebro un daño hipóxico isquémico extenso. Para mantenerla con vida, fue transitoriamente conectada a un ventilador mecánico; se le practicó una traqueotomía y posteriormente una gastrostomía percutánea, la que mediante una bomba de infusión la mantuvo nutrida e hidratada. Los médicos determinaron que todo se debió a un trastorno del metabolismo del potasio relacionado a la dieta para adelgazar, lo que provocó un paro cardíaco el que a su vez produ- jo un daño cerebral isquémico. Semanas después salió del coma, sin embargo, nunca recobró la conciencia, permaneciendo en estado vegetativo.

Según Gary Fox, abogado de los Schiavo en la demanda contra el ginecólogo que la atendía, hizo ver que este accidente fue una manifestación del estado médico de su defendida. M ichael ganó una indemnización de más de un millón de dólares en el juicio en contra del ginecólogo que no había detectado el trastorno del potasio que fue la causa del paro cardíaco. En 1998, cuando varios neurólogos independientemente concordaron en que su esposa se encontraba en un estado vegetativo permanente, Michael tomó la determinación de cumplir con el deseo que ella le habría manifestado, de no mantenerla con "vida artificial". Un deseo que Terri no dejó por escrito y los Schindler, padres de Terri, sostuvieron que su hija "jamás había expresado que la dejaran morir por inanición", por lo que emprendieron una batalla judicial contra su yerno.

Su esposo en cambio, sostuvo que ella lo instruyó hace varios años para que no la dejasen con "vida artificial". Con ese argumento obtuvo una autorización judicial para suspender la alimentación que Terri Schiavo recibía a través de la sonda. Se trataría de conducirla a una muerte paulatina y, según los médicos, indolora y sin sufrimientos.

Los padres de la señora Schiavo, Bob y M ary Schindler, tuvieron una posición radicalmente distinta. Ellos están por principio en contra de que a su hija se le deje morir pero, además, aseguran que mantiene la conciencia y que es capaz de pensar, sentir e incluso de expresarse.

1 Comité de Ética SONEPSYN. 
Durante los 7 años que se prolongó la bataIla legal entre los padres de Terri y su esposo quien era su representante legal, él insistió que su esposa le había manifestado el deseo de no querer vivir en un estado de gran incapacidad, aunque nunca lo dejó por escrito. Era dependiente de la alimentación a través de la sonda, aunque respiraba en forma espontánea y, de acuerdo a la evaluación de 4 neurólogos, un radiólogo y su médico tratante, estaba total e irreversiblemente desconectada del ambiente que le rodeaba. Un neurólogo y un radiólogo elegidos por los padres de Terri hicieron ver que quizás podría mejorar con oxígeno hiperbárico y vasodilatadores. El tribunal dictaminó que las pruebas presentadas eran evidencia suficiente para el diagnóstico de estado vegetativo permanente. EI TAC de cerebro era concordante con una grave atrofia cerebral y los EEGs estaban severamente anormales.

Durante esta contienda legal Terri fue desconectada de la sonda que la alimentaba y vuelta a conectar en tres ocasiones, mediante diversos recursos legales. Los padres de Terri hicieron uso de todos los medios que hubo disponibles para mantener su alimentación en base a diversos argumentos. Hicieron ver que Michael debido a su relación con otra mujer y haber tenido dos hijos con ella debía ser removido de la condición de representante legal de Terri. Solicitaron a Michael que se divorciara de su hija o renunciara a sus derechos como tutor legal, y lo acusaban de adulterio, puesto que él había rehecho su vida con otra mujer. Hacen ver que debido a que Terri era una católica devota habría optado por continuar con vida, a pesar de la condición en que se encontraba. Además insistían en que el estado de su hija no era el de un estado vegetativo, sino que un estado de conciencia mínimo y que con nuevas terapias podía recuperarse. A esta opinión se sumó la del gobierno del estado de Florida haciendo ver que en el país se estaba confundiendo la santidad de la vida con lo que es calidad de vida.

El conflicto involucró al Congreso estadounidense, que aprobó una ley especial para llevar el caso ante la justicia federal, al presidente George
W. Bush (que interrumpió sus vacaciones para firmar la ley) y a su hermano Jeb, gobernador de Florida.

El portavoz vaticano Joaquín Navarro-Valls condenó en una declaración la retirada de alimento y agua que significaba la muerte de Schiavo. En una declaración Navarro-Valls describió la situación de Terri como "una aceleración arbitraria de la muerte". También expresó su confianza en que la experiencia condujera a la opinión pública a una mayor concienciación de la dignidad humana y a mejorar las salvaguardas legales de la vida.

En una declaración el cardenal William Keeler, presidente del comité de actividades pro vida del episcopado norteamericano, comentaba que su situación trajo a la luz una cuestión crítica: "Para ser una sociedad verdaderamente humana, ¿cómo deberíamos proteger a aquellos pacientes más desamparados que no pueden hablar por sí mismos?". Y añadía: "Recemos para que esta tragedia humana conduzca a nuestra nación a un mayor compromiso para proteger a los pacientes desamparados y a todos los más débiles de entre nosotros".

Los pacientes privados de alimento y agua mueren antes de sed, y esto no es una experiencia agradable, observaba el Dr. David Stevens, director ejecutivo de la Christian Medical Association en Estados Unidos. También se hizo ver la conclusión de la Conferencia de Obispos Católicos de EE.UU., en 1994 que estableció claramente que es obligatorio dar agua y alimentos durante todo el tiempo que el beneficio derivado de ello sea mayor que el dolor o sufrimiento que se pueda agregar a un paciente (estamos hablando de sufrimientos graves). El agua y los alimentos no son considerados "medios extraordinarios", como las máquinas que mantienen la vida artificialmente cuando ha ocurrido la muerte total e irreversible del cerebro. En este caso también queda claro que aunque Terri estuviera en un "estado vegetativo persistente", esta complicación médica no es fatal. La muerte no es inminente y la expectativa de vida es larga, como hasta ahora lo ha demostrado Terri, sobreviviendo 
más de diez años. De hecho, el solo término de "estado vegetativo persistente" es una ofensa a la dignidad de la persona, ya que da a entender que la persona se valora por la utilidad que tiene para la sociedad, en este caso ninguna, porque es considerada, de forma ofensiva, como un "vegetal".

En medio de toda esta controversia el matrimonio Schindler pudo llevar su caso al sistema judicial federal, Ilegando hasta el Tribunal Supremo de EE.UU., que, como todas las instan- cias anteriores, negó sus demandas y falló en favor de no volver a conectarla a la sonda el 24 de marzo de 2005. Al no haber otras instancias a las cuales recurrir, la mujer se mantuvo sin alimentación por la orden judicial que se había dictado el 18 de marzo hasta su muerte, el 31 de $M$ arzo.

La autopsia demostró que el cerebro de Terri pesaba 615 gramos y correspondía a lo que se observa en pacientes que han permanecido en un estado vegetativo permanente. 